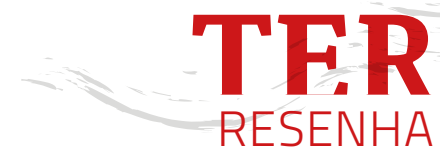

\title{
A FABRICAÇÃO DA CRENÇA POR IMAGENS, SONS, OBJETOS E CORPOS
}

DoI dx.doi.org/10.11606/issn. 25253123.gis.2020.162688

ORCID orcid.org/0000-0003-1741-5811
Meyer, Birgit. 2019. Como as coisas importam: uma abordagem material da religião. Organizado por E. Giumbelli, J. Rickli e R. Toniol. Porto Alegre: Editora da UFRGS.

\section{MARCUS VINÍCIUS BARRETO}

Universidade de São Paulo, São Paulo, SP, Brasil 05508-010 - ppgas@usp.br

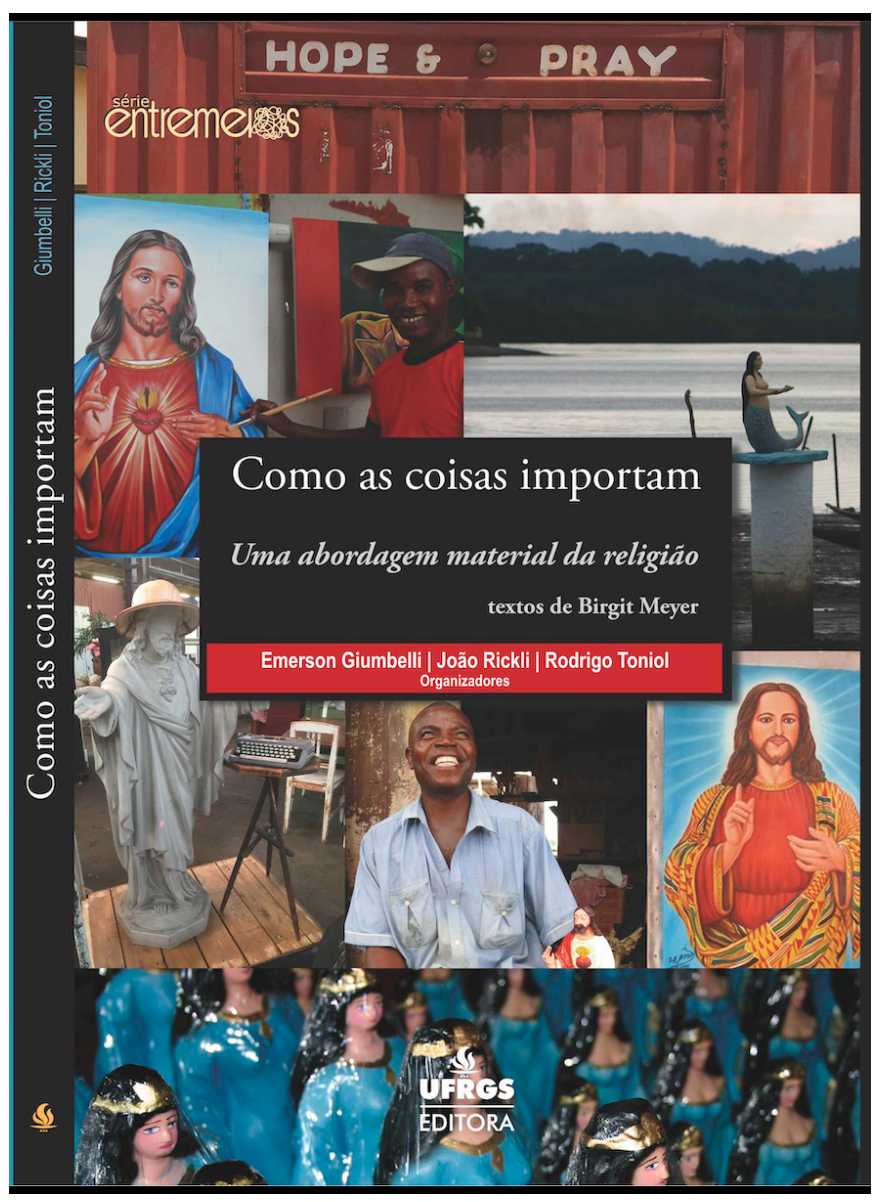


O universo da "religião", enquanto produto histórico do Ocidente, vem sendo colocado sob o escrutínio de cientistas sociais que, há algumas décadas, criticam binarismos clássicos, a exemplo da contraposição entre a noção de magia e o campo religioso - caso do antropólogo Stanley Tambiah que, no início dos anos 1990, publicou a intrigante obra Magic, science, religion and the scope of rationaliy (1990) - ou, ainda, da rearticulação desse mesmo campo em todo e qualquer contexto de maneira acrítica - um dos temas abordados por Talal Asad, entre outros. Todavia, o esforço analítico dos intelectuais citados não é um caso isolado na área das ciências sociais, muito menos de um ponto de vista exclusivo sobre a questão religiosa.

Na esteira de uma produção teórica que se empenha em tensionar os pilares erigidos pelo projeto de modernidade, algumas metanarrativas entraram em colapso a partir de uma crítica mordaz e subsumida ao prefixo "pós". Nesse sentido, muitos estudiosos perceberam que seus objetos de pesquisa possuem agência, e as chamadas "viradas", dentre as quais encontramos a virada material, funcionam como uma espécie de diagnóstico da falência moderna ou de uma epistemologia construída segundo a lógica de pares opositivos. Poder, corpo, imagens e coisas são alguns dos tópicos que fazem da virada material importante marco na história das humanidades, principalmente se considerarmos o alcance inegável de autores como Michel Foucault, Judith Butler, Hans Belting, Alfred Gell, Bruno Latour etc.

Nessa linha de raciocínio, e tomando o tema da religião como pano de fundo, considero a tradução para o português de alguns textos escritos pela antropóloga alemã Birgit Meyer um bom exemplo de interseccionalidade - para cotejar o termo da moda - com ousadia, método e presença. Antes de me debruçar em cada termo sugerido, adianto que a dimensão material da religião é o argumento central da obra e, dessa feita, as escolhas teóricas da autora suscitam alguma aproximação com uma das premissas da virada material: a revisão crítica do significado das “coisas". Entretanto, na visão de Meyer (2019), a crítica à esfera da religião tal qual postulada por uma tradição de estudos - sobre a qual falarei mais adiante - implica superar exatamente o significado em detrimento de um método que maximize as próprias "coisas". Ademais, a análise das "coisas" que importam para Meyer, ou sobre como elas importam em seu ousado projeto de pesquisa, certamente dialoga com a trajetória acadêmica dessa pensadora.

Birgit Meyer realizou pesquisas na área de antropologia e religiões comparadas, incialmente na Universidade de Bremen e posteriormente na Universidade de Amsterdam onde, na década de 1990, concluiu um doutorado sob a orientação de Johannes Fabian. Compondo o rol de pesquisadores 
africanistas, o sul de Gana é o campo de investigação escolhido por Meyer, que há 20 anos analisa a proliferação do pentecostalismo na esfera pública ganense. A autora observa que, a partir da Constituição democrática de 1992, o governo de Gana popularizou os meios de comunicação e, desde então, as mídias de massa propiciaram a onipresença de imagens cristãs, principalmente na produção de videofilmes.

A vivência em campo, bem como a repercussão de suas etnografias, renderam-lhe um cargo de docência na Universidade de Utrecht onde, desde 2016, ela coordena o projeto "Religious matters in an entangled world" junto com outros pesquisadores de diferentes regiões do mundo. A relação entre religião e mídia ou, principalmente, a compreensão da própria religião como mídia é o grande cerne desse projeto de pesquisa, cujo objetivo é investigar a presença da religião em edifícios, imagens, objetos, comidas, corpos, textos etc. Alguns dos mais importantes artigos escritos por Meyer e publicados em prestigiadas revistas científicas de Europa e Estados Unidos foram reunidos pelos antropólogos Emerson Giumbelli, João Rickli e Rodrigo Toniol naquela que, por enquanto, é a primeira obra da autora editada no Brasil. Como roteiro de leitura para a coletânea de artigos, me aproprio dos termos ousadia, método e presença enquanto palavras-chave que permitem apreender algumas propostas de Meyer.

Primeiro, diria que sua obra é ousada porque rejeita uma perspectiva mentalista mediante a qual o campo das humanidades - apoiando-se em abordagens semânticas e devedoras de uma tradição iluminista que enfatiza o conteúdo e o significado das coisas -, por um lado, faz críticas à questão religiosa, partindo de noções como ilusão fictícia e falsa consciência, haja vista a embocadura teórica abraçada por Feuerbach, Marx, Nietzsche e Freud; por outro, olha o "fenômeno" religioso com "bons olhos", a exemplo de Durkheim e Rudolf Otto em suas respectivas análises sobre fato social e esfera do sagrado.

Segundo, ao criticar o ponto de vista "de dentro", Meyer propõe um método que vai ao encontro de algumas propostas da virada material. Em outras palavras, "como estudar a religião" é a tônica dos seus artigos, e tal comprometimento metodológico, na visão da autora, tanto implica assumir uma postura "pós-secularista", que estremece o suposto declínio da religião na vida pública - de acordo com o paradigma da secularização -, quanto demanda uma atitude de "rematerialização" na própria maneira de estudar o objeto, posto que considerar a religião enquanto um arrazoado de significados é uma escolha que acaba por negligenciar sua tangibilidade em corpos, imagens e objetos.

Terceiro, tomando como referência alguns contextos pós-coloniais e de diversidade religiosa, caso de Gana, a antropóloga afirma que a religião 
está presente na vida pública, e essa presença é fruto de formas materiais que se tornam visíveis a depender da correlação de forças políticas. Em suma, como apontam Giumbelli, Rickli \& Toniol (2019), Meyer trouxe grandes contribuições ao perceber que a atuação em um espaço público está conectada a um processo que envolve atributos, competências corporais ou, de maneira geral, mídias que legitimam uma voz pública. Vamos por partes.

No primeiro artigo, "De comunidades imaginadas a formações estéticas", Meyer introduz os pressupostos do seu programa de pesquisa colaborativa sobre mídia, religião e formação de comunidades. Já no começo do texto ela propõe um interessante diálogo com Benedict Anderson, reconhecendo que no processo de reconfiguração de Estados-nações pós-coloniais há, de fato, uma emergência de comunidades, dentre as quais se encontram as chamadas comunidades religiosas. Contudo, na visão de Meyer, somente olhar para essas comunidades pela perspectiva da imaginação é uma análise que oblitera os mecanismos de construção do imaginário; ou seja, os partícipes das comunidades não somente imaginam e constroem identidades, mas produzem efeitos de autenticidade e realidade. Consequentemente, as imaginações tornam-se tangíveis para além do domínio das ideias.

É neste ponto que Meyer critica toda uma tradição da qual a antropologia do significado ou dos símbolos, bastante disseminada no contexto estadunidense, é herdeira. A autora adverte que os significados são tangíveis na medida em que são compartilhados não somente por ideias, mas principalmente por um ambiente social que as materializa por meio do espaço, da arquitetura, da performance ritual e da indução de sensações corporais. É essa materialidade que nos mostra o papel desempenhado por coisas, mídias e corpos nos processos efetivos de produção de comunidades. Contudo, as negociações e o alcance dessas formas materiais ocorrem no bojo de um processo que a autora denomina de "formação estética" (Meyer, op. cit., p. 51).

Ao afastar-se de uma noção de "estética" restrita à esfera das artes, tal qual proposta por Kant, Meyer retoma o sentido aristotélico de aisthesis enquanto percepção dos objetos no mundo através dos cinco modos sensoriais, colocando em relevo o poder incisivo de imagens, sons e textos sobre os corpos. Nessa aposta, a antropóloga alarga as possibilidades de estudar as religiões, enfatizando o estilo em vez do significado, a aparência em vez da essência, e o meio em vez da mensagem. Dessa feita, a religião se faz presente em muitos lugares porque, enquanto prática de mediação, ela interage com e se espraia por um conjunto de mídias, sejam elas tecnológicas - cinema, rádio, fotografia, televisão, computadores - ou não - incenso, ervas, animais sacrificiais, ícones, livros sagrados, pedras, rios, o próprio corpo humano etc. 
Ao retomar alguns pilares que erigiram o projeto de modernidade no século XIX, a antropóloga, ao longo do segundo artigo, "Religião material: como as coisas importam”, remete a um clássico binarismo que até hoje aparece arraigado nas investigações acadêmicas sobre religião: a crença e o significado que revestem a imaterialidade do espírito em contraposição às questões que envolvem poder, práticas e materialidades. Segundo a autora, essa oposição alimentou a ideia secularista mediante a qual a religião foi projetada para o âmbito da interiorização e do privado. Ocorre que, contrariamente aos anseios de uma ciência avessa à presença pública do religioso, algumas ocorrências cotidianas como sons, silêncios, cheiros, toques, formas, cores e afetos não conformam única exclusivamente os espaços de "manifestação do sagrado", mas também o próprio tecido social do qual a esfera pública é constituída. Ainda na visão de Meyer (op. cit.), a percepção da "extraordinariedade do ordinário" ou da "ordinariedade do extraordinário" foi uma das grandes contribuições epistêmicas e políticas da virada material.

No que concerne ao terceiro artigo, "Há um espírito naquela imagem", a autora expõe alguns dados curiosos acerca do campo de pesquisa. Ao constatar uma presença pública das igrejas pentecostais carismáticas no sul de Gana, Meyer formula a hipótese segundo a qual o poder do pentecostalismo nessa região, para além das igrejas, é fruto da liberação das mídias de massa audiovisuais e de sua incorporação pelos atores religiosos. Ao mesmo tempo, ela observa que a expansão visual e auditiva do pentecostalismo no rádio, na televisão, em cartazes e adesivos ocorre em uma tensa zona de contato com a chamada "religião africana tradicional". Contrapondo-se à ideia de "perda da aura" em virtude da reprodutibilidade técnica de imagens, uma das teses de Walter Benjamin, Meyer defende o argumento de que as imagens cristãs midiaticamente replicadas no contexto ganense podem ser "presenças perturbadoras que colocam seus espectadores sob encantamento" (Ibid., p. 116).

Ao observar rituais de louvação diante de imagens de Jesus, a autora depara-se com uma atitude "ambivalente" por parte dos convertidos: ao passo que demonstram adoração diante das imagens, eles deslizam em uma atitude de temor. Na visão da antropóloga, a dúbia relação decorre de um potencial de reversibilidade que essas imagens carregam; ou seja, as imagens produzem uma inversão radical quando aquilo que se parece com Jesus tem a capacidade de tornar-se "demoníaco". Isso posto, Meyer conclui que por trás das imagens operam práticas sociais de ação e observação. Por outro lado, a aparente dubiedade não pode ser compreendida como oposição, mas enquanto uma dinâmica simbiótica das relações entre o campo do pentecostalismo e algumas tradições religiosas autóctones. 
No entanto, para chegar a tais conclusões, a autora recorre a ferramentas analíticas situadas conceitual e historicamente. No quarto artigo, "Mediação e a gênesis da presença: rumo a uma abordagem material da religião", ela recupera alguns pontos de sua metodologia de estudo, enfatizando a importância de revisar abordagens, conceitos e métodos que modelam as tradicionais práticas de pesquisa sobre religião. Para tanto, os processos de mediação que englobam a materialidade do campo religioso, bem como a gênesis de sua presença, permitem não somente rever a metodologia, mas também o conceito, o papel e o lugar da religião. Nesse bojo, a fim de fundamentar o argumento sobre a presença perturbadora das imagens cristãs no contexto ganense, Meyer retoma a noção de "fetiche".

Áreas fronteiriças coloniais como Gana possibilitam descentralizar o estudo da religião para além da Europa, onde, a partir da crítica à religião em decorrência da ascensão do racionalismo durante o período iluminista, o discurso do fetichismo transformou a noção de fetiche em categoria de acusação, dada sua capacidade de sustentar, na ótica dos racionalistas, estruturas "irracionais" que mantinham o status quo do Ancien Régime. Definido como fenômeno decorrente dos encontros mercantis entre portugueses e africanos - no final do século XV -, o termo fetiche alude a objetos que, embora moldados pela mão humana, "possuem vida própria". Em outras palavras, a capacidade de agência desses objetos foi lida como uma ameaça à razão e ao progresso, fato que ensejou os racionalistas a conclamar sua destruição.

Com base na história do fetiche, Meyer formula mais uma hipótese: a perturbação causada pelas imagens cristãs, como por ela observado, dialoga com algumas dinâmicas inscritas nas práticas religiosas dos povos que habitam o sul de Gana, caso dos Ewé. Quer dizer, a despeito da condenação aos deuses das religiões autóctones, compreendidos como "ídolos" na perspectiva do discurso cristão, os Ewé, mesmo convertidos ao cristianismo, mantiveram no campo pentecostal uma postura pragmática tal qual nas religiões tradicionais. Em contrapartida, o próprio campo pentecostal que, juntamente com o governo de Gana e a proliferação das mídias de massa, possibilitou a replicação de imagens cristãs, ofereceu aos convertidos "formas e padrões religiosos concretos para atuar e acessar o poder do Espírito Santo” (Ibid. p. 182).

Assim, conclui Meyer, a conjunção entre materialidade e pragmatismo pode ser um indício da presença bem-sucedida do pentecostalismo. Nessa linha de raciocínio, abordar materialmente a religião é um exercício de deslocamento das orientações mentalistas centradas na linguagem - o que as pessoas dizem? o que isso significa? - para um foco direcionado às práticas - o que as pessoas fazem? Quais sentidos são 
invocados no corpo? Quais materiais são usados? -, proposta já contemplada pelo conjunto de viradas: linguística, corporal, icônica e material. Em se tratando da virada material, a agência das "coisas" trouxe para o centro da questão os modos concretos de fabricação do social - vide Latour - ou, podemos dizer com Birgit Meyer, os modos religiosos de "fabricar a crença".

No quinto artigo, "Imagens do invisível: cultura visual e estudos da religião", a capacidade que a imagem tem de presentificar o invisível ou o ausente por meio de um ato performativo é o ponto discutido por Meyer. A autora dialoga com alguns teóricos da história das artes e da antropologia da imagem, como W. J. T. Mitchell e Hans Belting. De acordo com Meyer, a produção em massa de imagens devocionais no sul de Gana, a exemplo dos pôsteres de Jesus ou de representações de espíritos malignos como fantasmas, sereias e bruxas, é devedora de uma cultura visual proeminente nesse contexto e tributária tanto das religiões tradicionais quanto do cristianismo. Sendo assim, adverte a autora, um estudo minimamente rigoroso em um contexto como esse não poderia negligenciar "o papel das formas materiais nos modos religiosos de criar o mundo" (Ibid., p. 207).

No sexto e último artigo, “Como capturar o “Uau!”, a antropóloga usa uma interjeição que decorre da sensação de admiração e encanto ou dos efeitos experimentados pelo corpo na relação com o "sobrenatural". Se, pelo exposto no conjunto da obra, essa naturalidade e transcendência são fabricadas, Meyer posiciona-se no meio termo entre não tomar o sobrenatural como uma evidência e muito menos descartá-lo enquanto uma ilusão irracional. Nesse sentido, ela reforça a crítica à antropologia da religião que, seguindo um viés fenomenológico, tende a defender 0 ponto de vista "desde dentro". Para Meyer, ao contrário, um ponto de vista "desde fora" é indispensável uma vez que a atitude de "levar a sério" a religião encontra seus limites quando o universo religioso é tomado de maneira acrítica. Considerar a importância eminente do corpo, das sensações e das emoções na construção de mundos, como vêm sugerindo muitos teóricos das humanidades, mostra-se um caminho transformador para o estudo da religião.

A coletânea de artigos é encerrada com uma interessante entrevista realizada pelos organizadores da obra com Birgit Meyer, sobre a qual não tecerei comentários, exceto quanto ao fato de que os futuros leitores provavelmente experimentarão um outro tipo de "Uau!". Julgo importantes algumas considerações finais.

Primeiro, a obra de Meyer traz pouquíssimos dados etnográficos. Na própria coletânea, a autora assume essa ausência e, indo ao encontro de 
pensadores que acumulam amplo material de pesquisa, e talvez estejam ávidos por codificar uma epistemologia, ela justifica sua preferência em investir na abordagem teórico-metodológica. De fato, enquanto uma metodologia pós-secularista de estudo da religião - assim considero sua obra -, a coletânea cumpre seu papel de provocação e transformação no campo acadêmico.

Segundo, e aqui me permito ir um pouco além da obra, mas não do projeto de Birgit Meyer, a metodologia proposta pela antropóloga e seus colaboradores do "Religious matters in an entangled world" teve, anteriormente, uma acalorada reverberação no Brasil com as publicações do antropólogo da Universidade de Amsterdã e interlocutor de Meyer, Marttijs van de Port, que realizou uma etnografia sobre o Candomblé a partir de um trabalho de campo na cidade de Salvador (Bahia). Nessa pesquisa, van de Port desafiou tradicionais métodos de estudo sobre o candomblé; ou seja, a maioria das etnografias publicada sobre esse universo preconiza que o candomblé tem de ser estudado seguindo um tripé: um determinado templo - mais comumente chamado de terreiro pelos praticantes -; um sacerdote que coordena esse templo e que seria a voz "legitimada" para falar; e, finalmente, um rito de iniciação.

Munido dessas leituras e observando a metodologia mais recorrente, antes de chegar em campo, van de Port não colocou em questão as premissas dos pesquisadores que se dedicam a investigar o candomblé: à primeira vista, tratava-se de um universo fechado, secreto e, portanto, de difícil acesso. Todavia, ao adentrar o campo, o antropólogo se deparou com um cabelereiro que falava acerca do candomblé e seus rituais de maneira muito íntima enquanto cuidava do cabelo do próprio antropólogo. Outra surpresa foi a estátua de Iemanjá - uma das divindades do candomblé - vista por van de Port em um bar frequentado pelo público LGBT.

Em suma, na contramão de um ponto de vista "de dentro", o antropólogo percebeu uma presença do candomblé na esfera pública de Salvador, bem como sua tangibilidade, não somente pela fala dos iniciados ou sacerdotes, mas pelos corpos de vários simpatizantes, pelas indumentárias, pelos meios de comunicação daquele contexto, pelos festejos populares, pela culinária baiana e pelas pautas coordenadas por três movimentos sociais: o movimento negro, o LGBT e o ambientalista.

O impacto do trabalho de van de Port rendeu um artigo escrito pelo antropólogo Ordep Serra (2012), professor emérito da Universidade Federal da Bahia que dedicou sua carreira a pesquisar o candomblé. No artigo, Serra reconhece o olhar inovador de van de Port, mas refuta as críticas do antropólogo holandês sobre métodos de estudo um tanto quanto ultrapassados e desmaterializados. 


\section{REFERÊNCIAS BIBLIOGRÁFICAS}

Giumbelli, Emerson; Rickli, João \& Toniol, Rodrigo. 2019. "Introdução: percursos e conceitos de Birgit Meyer". In: Meyer, Birgit. 2019. Como as coisas importam: uma abordagem material da religião. Porto Alegre: Editora da UFRGS.

Meyer, Birgit. 2019. Como as coisas importam: uma abordagem material da religião. Organizado por E. Giumbelli, J. Rickli e R. Toniol. Porto Alegre: Editora da UFRGS.

Serra, Ordep. 2012. Debates do NER, Porto Alegre, Ano 13, N. 22.

Tambiah, Stanley. 1990. Magic, science, religion and the scope of rationality. Cambridge: Cambridge University Press.

MARCUS VINÍCIUS BARRETO é doutorando em Antropologia Social na Universidade de São Paulo (USP). Desde 2013, realiza pesquisa na área de Religiões Afro-Brasileiras. Atualmente, é membro do grupo de pesquisa "Religião, Direito e Secularismo: a reconfiguração do repertório cívico no Brasil contemporâneo" (USP/FAPESP/Cebrap). E-mail: marcusrbarreto@yahoo.com

Licença de uso. Este artigo está licenciado sob a Licença Creative Commons CC-BY. Com essa licença você pode compartilhar, adaptar, criar para qualquer fim, desde que atribua a autoria da obra. 